\title{
Transmembrane protein tyrosine phosphatase IA-2 (ICA512) is expressed in human midgut carcinoids but is not detectable in normal enterochromaffin cells
}

\author{
J L Cunningham, J R Lopez-Egido, E T Janson, B Eriksson, \\ K Öberg and A E Gobl
}

Department of Medical Sciences, Endocrine Oncology Unit, Uppsala University Hospital, S-751 85 Uppsala, Sweden

(Requests for offprints should be addressed to A E Gobl, Email: Anders.Gobl@medsci.uu.se)

\begin{abstract}
A potential upregulation of receptor type protein tyrosine phosphatase IA-2 (ICA512) expression was detected by differential display and investigated in midgut carcinoid tumours. Normal intestine tissue and tumour tissue from 13 midgut carcinoid patients were studied by in situ hybridisation using an IA-2 ribonucleotide probe and confocal microscopy using specific IA-2 antibodies. Previously, it had been shown that IA-2 is located in the secretory granules of virtually all neuroendocrine cells. However, we found that IA-2 was not detectable in resting normal enterochromaffin (EC) cells of the small intestine, while high expression of IA-2 mRNA and protein was confirmed in both primary and metastatic carcinoid tissue. This difference in expression was not observed with chromogranin A or serotonin, two secretory granule hormones known to be expressed in EC cells, indicating that IA-2 was seemingly not necessary for the
\end{abstract}

basal production and packaging of these hormones. When comparing patients receiving biotherapy before operation with untreated patients, we found expression of IA-2 to be lower in tumours from patients that had been treated with a combination of $\alpha$-interferon and the somatostatin analogue, octreotide. There was no correlation between IA-2 expression and proliferation rates as measured by immunohistochemistry with antibodies against the Ki 67 antigen. Furthermore, we show that IA-2 is co-localised with serotonin in carcinoid tumours as well as in the pancreatic tumour cell line, BON1, which is interesting as serotonin secretion rate is presumably higher in tumour cells than in resting EC cells. Taken together, these findings may indicate a role for IA-2 in the later stages of the regulated secretory process.

Journal of Endocrinology (2000) 164, 315-322

\section{Introduction}

Full-length IA-2 (ICA512) was first isolated and characterised by Lan et al. (1994) and it is known to be an autoantigen in diabetes. Sequence homology analysis in different species indicates that IA-2 homologues exist in rat, mouse, and even Caenorhabditis elegans, suggesting a vital role in neuroendocrine function (Smith et al. 1996, Notkins et al. 1997). IA-2 encodes a transmembrane protein of 979 amino acids and features a region homologous to the catalytic domain of receptor type protein tyrosine phosphatases (RT-PTPs) (Lan et al. 1994, Rabin et al. 1994). It does not demonstrate phosphatase activity in assays with common PTP substrates (Rabin et al. 1992, Lan et al. 1994, Magistrelli et al. 1996). This absence of activity is due to two sequence deviations in the PTP core domain; however, the possibility of a very narrow substrate specificity cannot be ruled out (Magistrelli et al. 1996).

IA-2 is located in regulated secretory granules of neuroendocrine tissues (Smith et al. 1996, Solimena et al.
1996) and has been proposed to be a marker for neuroendocrine differentiation in lung cancer (Xie et al. 1996). Furthermore, it has been shown that hormone stimulation of GH4C1 cells (a rat pituitary tumour cell line) results in stabilisation of IA-2 protein (Xie et al. 1996). This treatment leads to granulogenesis and the secretion of prolactin in a regulated manner (Gorr 1996, Xie et al. 1996). Based on these findings, IA-2 has been proposed to have a role in, or to be affected by, the regulated secretory process in either the granulogenesis or later secretory stages of neuroendocrine cells (Lan et al. 1994, Solimena et al. 1996, Lee et al. 1998).

Neuroendocrine cells have two known types of regulated secretion in addition to the constitutive secretory pathway. The secretion of hormones is controlled by mechanisms separate from the secretion of neurotransmitter molecules. Hormone secretory granules can vary in hormone content as well as in cellular location. This has led to speculation regarding different granule populations and the possibility of separate hormone secretory 
mechanisms (Hendy et al. 1995, Langley \& Grant 1997, Portela-Gomes 1997).

Classical midgut carcinoid tumours, arising from enterochromaffin (EC) cells of the small intestine, are slow growing and give symptoms due to excessive hormone secretion (Tiensuu Janson \& Oberg 1996). However, secretion mechanisms and regulation in these tumours are not yet understood. Equally uncharacterised are the changes in gene expression that distinguish a normal neuroendocrine cell from a tumour cell.

We used the differential display method as a means of revealing these changes in gene expression patterns. Results from differential display experiments indicated an increase in IA-2 mRNA expression in carcinoid tumours compared with normal endocrine cells of the intestine. In the present investigation, we have confirmed this differential IA-2 expression at the mRNA and protein level, and have provided further support for a role of IA-2 in regulated secretion through the examination of tissues obtained from normal intestine, and from primary and metastatic tumours from 13 patients who have undergone varied biotherapy.

\section{Materials and Methods}

\section{Patients}

Thirteen patients ( 6 men and 8 females) with midgut carcinoid tumours scheduled for abdominal surgery were studied. The median age was 57 years (range $41-71$ years). All patients had metastatic disease. The patient material tested represented both stable and progressive tumours and were divided into 4 treatment categories: untreated, treatment with $\alpha$-interferon or octreotide alone, or the two in combination. Medical treatment was administered prior to the operation (see Table 1). Nine patients had stable biochemical and radiological disease at the time of operation while five were in a progressive state (see Table 1). The patients had fasted for over $12 \mathrm{~h}$ before the operation material was obtained. During the operation, tissue from the primary tumour and the mesenteric metastasis was collected. For control purposes, normal small intestine tissue was also taken. All material was immediately frozen in liquid nitrogen and stored at $-70{ }^{\circ} \mathrm{C}$ until use.

\section{Cell culture and preparation of slides}

Cultures of BON1 cells (a pancreatic tumour cell line) (Evers et al. 1994) were grown in Dulbecco's modified Eagle's medium (DMEM, Life Technologies, Rockville, MD, USA) and F12K (1:1, Life Technologies) supplemented with $10 \%(\mathrm{v} / \mathrm{v})$ fetal calf serum and antibiotics until approximately $75 \%$ confluency. The cells were washed twice with PBS and trypsinated for $5 \mathrm{~min}$. The trypsin reaction was stopped by adding $10 \mathrm{ml}$ supplemented DMEM and the cells were centrifuged and resuspended at a concentration of $1 \times 10^{6}$ cells $/ \mathrm{ml}$. Two hundred microlitres of the suspension was cytocentrifuged onto silane-treated glass slides. The slides were frozen and stored at $-70{ }^{\circ} \mathrm{C}$ until use.

\section{Differential display}

Total RNA was isolated from normal intestine, primary midgut carcinoid tumour and metastatic carcinoid tumour as described (Chomczynski \& Sacchi 1987). The RNA was treated with DNase 1 to eliminate contaminating genomic DNA. First strand cDNA was synthesised using $2 \mu \mathrm{g}$ RNA as described by the manufacturer (Delta Differential Display kit, Clontech, Palo Alto, CA, USA). Differential display PCR was performed using cDNA and primers in the kit in the presence of $\left[\alpha_{-}{ }^{33} \mathrm{P}\right] \mathrm{dATP}$ (Amersham-Pharmacia Biotech, Uppsala, Sweden). PCR products were analysed on $5 \%$ polyacrylamide/ $8 \mathrm{M}$ urea gels. After drying the gels and performing autoradiography with phosphoimager screens (Molecular Dynamics, Sunnyvale, CA, USA), differential expressed bands were excised with a sterile scalpel. Bands were eluted by boiling in water for $5 \mathrm{~min}$, reamplified by PCR and then cloned into plasmid (TOPO TA Cloning kit, Invitrogen, San Diego, CA, USA). DNA sequencing was performed using dye terminator chemistry and an ABI 373A sequencer (Perkin-Elmer, Foster City, CA, USA).

\section{Antibodies}

The following antibodies were used. A rabbit polyclonal antiserum against IA-2 (89-59) (Bayer, Leverkusen, Germany), initially created by immunisation of rabbits with a fragment of the cytoplasmic domain encompassing amino acids 643-979 (Solimena et al. 1996), was used at a dilution of 1:400. A mouse monoclonal anti-chromogranin A (CgA; LK2H10) (Boehringer Mannheim Mannheim, Germany) was used at a dilution of 1:2000. A mouse monoclonal anti-serotonin (DAKO, Copenhagen, Denmark) was used at a dilution of 1:10. Fluoresceinisothiocyanate (FITC)-labelled swine anti-rabbit immunoglobulin $\mathrm{G}(\mathrm{IgG})$ (DAKO) was used at a dilution of 1:40. Cy3-labelled, goat $\mathrm{F}\left(\mathrm{ab}^{\prime}\right)$ antimouse $\operatorname{IgG}$ (Cederlane Laboratories, Hornby, Ontario, Canada) was used at a dilution of 1:200. Mouse monoclonal Ki 67 antibody (Dianova, Hamburg, Germany) was used at a dilution of 1:100. Biotinylated horse anti-mouse immunoglobulins (Vector Laboratories, Burlingame, CA, USA) were used at a dilution of 1:200.

\section{Indirect immunofluorescence}

Tissues were cryosectioned and fixed in fresh and filtered $4 \%$ paraformaldehyde/PBS for $4 \mathrm{~min}$. Serum and primary antibody were diluted in PBS containing 2\% BSA and 
Trasylol (1:7; Bayer). Blocking was performed with serum (dilution 1:10 of normal swine serum or normal goat serum) for $10 \mathrm{~min}$. Primary antibodies were applied to the tissues and incubated at $4{ }^{\circ} \mathrm{C}$ overnight in a moist chamber. Unbound antibody was removed by washing, thrice for $5 \mathrm{~min}$, in PBS. Secondary antibodies were incubated for $40 \mathrm{~min}$ at room temperature. Unbound antibody was removed by washing in PBS, four times for $5 \mathrm{~min}$. Slides were mounted with coverslips and anti-fading mounting solution (DAKO).

\section{Confocal microscopy}

All immunostained sections were examined with a Zeiss LSM 410 laser scan microscope. The laser-scanning microscope was used in a dual parameter setup according to the manufacturer's specifications, using dual wavelength excitation at 488 and $543 \mathrm{~nm}$. Emission spectra were separated by the standard dichroic mirrors and barrier filters. For scanning of the stained sections, $\times 40$ and $\times 60$ oil immersion objectives (numerical aperture 1.4) were used. The images were captured at the same gain in the camera's linear range, digitised and stored on optical disks. Where intensity comparisons were to be made, all sections were stained with the same antibody, with the same immunostaining procedure, and were captured with identical parameters (including contrast, brightness, magnification and pinhole) at identical times. The intensity of IA-2 staining in tumour cells in the treatment groups was evaluated independently by three investigators. Double stains were performed with monoclonal antibodies against a neuroendocrine cell marker, CgA (red pseudocolour) (Hendy et al. 1995), and with polyclonal antibodies against IA-2 (green pseudocolour). Co-localisation of serotonin (red pseudocolour) and IA-2 was examined and compared with the co-localisation of CgA and IA-2 in BON1 cells. Co-localisation was estimated by adjusting the channels separately to subtract background. Co-localisation was artificially assigned yellow colour.

\section{In situ hybridisation}

Tissue samples were cryosectioned into $5 \mu \mathrm{m}$ sections and fixed in $4 \%$ paraformaldehyde/PBS for $3 \mathrm{~min}$ at room temperature. Slides were stored in $70 \%$ ethanol at $4{ }^{\circ} \mathrm{C}$ until use.

A 698 bp IA-2 cDNA fragment (nucleotides 650-1347) was generated by PCR using $10 \mathrm{ng}$ of a human brain plasmid cDNA library as template. This region of the IA-2 sequence was used as probe since it is specific, showing no homology to other known receptor-type protein tyrosine phosphatases as determined with the Align program of the Lasergene software package (DNASTAR, Madison, WI, USA). After purification, the PCR band was cloned in pZero-2 vector (Invitrogen) using standard techniques. The IA-2 sequence was confirmed by DNA sequencing on an ABI 373 DNA sequencer (Perkin-Elmer) and DyeDeoxy terminator chemistry. As a positive control for neuroendocrine tissue, a $211 \mathrm{bp} \mathrm{CgA}$ cDNA probe (nucleotides 915-1125) cloned into pZero-2 was used. Antisense and sense ribonucleotide probes were transcribed from linearised plasmids using $\alpha-{ }^{35}$ S-labelled UTP $(>1000 \mathrm{Ci} / \mathrm{mmol}$; Amersham-Pharmacia Biotech) and SP6 or T7 RNA polymerase (Life Technologies, USA) as described before (Gobl et al. 1988).

Consecutive sections from each sample were hybridised separately with antisense $\mathrm{CgA}$, and sense as well as antisense IA-2 ribonucleotide probes. In situ hybridisation was carried out as described before (Gobl et al. 1988). Briefly, the slides were treated with acetic anhydride followed by Tris- $\mathrm{HCl}$ buffer containing glycine. About $0.5-1 \mathrm{ng}$ probe in $20 \mu \mathrm{l}$ probe solution was hybridised to cells overnight at $50{ }^{\circ} \mathrm{C}$ in a humidified chamber. The slides were then washed and treated with RNase A, washed again, dehydrated in ethanol and then autoradiographed with NTB-2 nuclear track emulsion (Eastman Kodak, Rochester, NY, USA) for 14 days. The developed slides were counterstained with haematoxylin solution ( $7.5 \mathrm{~g} / \mathrm{l}$; Sigma, St Louis, MI, USA) and examined in a light microscope.

\section{Immunohistochemistry}

Cryosections, $5 \mu \mathrm{m}$ thick, were fixed in ice-cold acetone for $10 \mathrm{~min}$. Endogenous peroxidase activity was blocked with $0.3 \%$ hydrogen peroxide in PBS for $30 \mathrm{~min}$ and endogenous avidin-binding activity was blocked by sequential incubation with avidin and biotin for $15 \mathrm{~min}$ each using a blocking kit (Vector Laboratories). Unspecific binding of secondary antibody was blocked by incubation with normal horse serum using a dilution of 1:5 in PBS. Incubation with primary antibody was performed at room temperature for $1.5 \mathrm{~h}$ in a humidified chamber, and the sections were then incubated with biotinylated horse anti-mouse immunoglobulin. The immunoreaction was visualised using a Vectastain Elite $\mathrm{ABC}$ kit (Vector Laboratories) with 3-amino-9-ethylcarbazole in dimethylsulphoxide as chromogen and $0.02 \%$ hydrogen peroxide as substrate. Finally, the sections were counterstained with Mayer's haematoxylin. As a marker for proliferation and malignancy, we used a monoclonal Ki 67 antibody which reacts with a nuclear antigen expressed in all phases of the cell cycle except G0 (Pelosi et al. 1996). Sections were analysed at a magnification of $\times 1000$, and positive cells were counted in three different areas of maximum number of positive cells compared with negative cells using a $1 \mathrm{~cm}$ grid, and expressed as mean percentage positive cells of the total cell number.

\section{Results}

The changes of gene expression patterns involved in carcinoid tumorigenesis are largely unknown. In an effort 


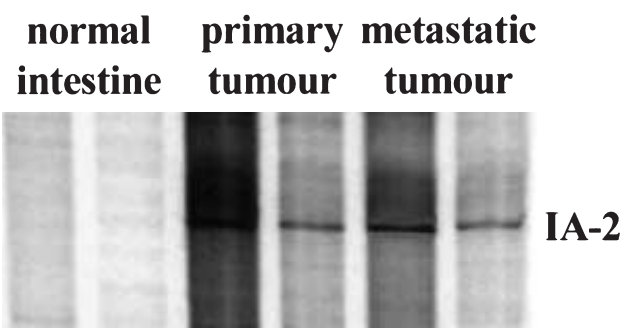

Figure 1 Differential display PCR was performed with CDNA synthesised from RNA isolated from normal intestine, primary tumour and metastatic tumour. The two lanes for each sample represent different dilutions of template cDNA (1:10 and 1:40 respectively) used for the differential display PCR.

to characterise gene expression differences in midgut carcinoids we used the differential display method. Total RNA was isolated from normal intestine, primary tumour and metastatic tumour. After cDNA synthesis and PCR amplification in the presence of radioactive dATP, PCR products were electrophoresed and differentially expressed bands isolated. As shown in Fig. 1, one band showed distinct upregulation in primary and metastatic tumour. This band was reamplified and subsequently cloned into plasmid. DNA sequencing of several clones showed that the band was IA-2.

In order to confirm the IA-2 mRNA upregulation in midgut carcinoids, in situ hybridisation was performed. Distinct expression of IA-2 mRNA was detected in all tumour tissue samples including primary tumours and metastases (Fig. 2D,G). However, IA-2 mRNA expression could not be detected in EC cells of normal small intestine (Fig. 2A). This lack of IA-2 mRNA in EC cells was not due to a general degradation of mRNA since chromogranin A mRNA was readily detected in the normal and tumour EC cells (Fig. 2C). Tissues incubated with sense probe did not demonstrate any specific hybridisation (Fig. 2B,E,H).

To investigate IA-2 expression at the protein level, indirect immunofluorescence and confocal laser microscopy were performed. Again, there was a distinct and strong expression of IA-2 in primary and metastatic tumours (Fig. 3C and D respectively), whereas normal EC cells showed no detectable IA-2 protein expression (Fig. 3A). However, the EC cells were clearly stained with monoclonal CgA antibody (Fig. 3B), and each section examined contained at least 10, and often over 30 chromaffin cells. Repeated stainings using different dilutions of antibody revealed no evidence of IA-2 staining in these cells. This result was confirmed using another EC cell marker, serotonin, in double stains of normal intestine with IA-2. In total, tissue from 13 patients was examined and all displayed similar results (Table 1).

In order to study IA-2 co-localisation with chromogranin A and serotonin (both hormones are known to be sorted to granules in the regulated secretory pathway) double immunofluorescent staining of carcinoid tumour tissue and of the pancreatic cell line, BON1, was performed. IA-2 and serotonin co-localisation was found to be greater than IA-2 and CgA co-localisation (Fig. 3G,H,I and $\mathrm{J}$ ).

To examine the effect of treatment regimes on IA-2 expression, the patients were divided into 4 treatment groups. Table 1 shows the relative IA-2 protein stain intensity. Combination treatment with both $\alpha$-interferon and octreotide resulted in lower levels of IA-2 (see also Fig. 3E and F). No significant differences in IA-2 expression could be detected between untreated patients and those who had undergone treatment with either $\alpha$-interferon or octreotide alone.

To estimate the proliferation rate of the different tumours, immunohistochemistry with monoclonal antibodies against Ki 67 antigen was performed. As shown in Table 1 , the majority of the tumours were shown to have a proliferation index below $5 \%$, which is generally classified as low. The range of cells proliferating was between 0 and 10\%, whereas IA-2 was expressed in the majority of tumour cells. Furthermore, proliferation differences found between primary and metastatic tumours were not reflected in IA-2 expression. There was no obvious correlation between proliferation rate and IA-2 expression in these tumours.

\section{Discussion}

Using differential display, in situ hybridisation and confocal microscopy, we found that IA-2, which is thought to be ubiquitous in cells of neuroendocrine origin and an intrinsic protein in the membrane of regulated secretory granules (Solimena et al. 1996), was not detectable in normal resting EC cells in the small intestine, while IA-2 was present in all midgut carcinoid tumours examined. To our knowledge, this is the first report of a lack of IA-2 expression in a peptide-secreting endocrine cell. In addition to this, we have presented data suggesting that the IA-2 expression is modulated by biotherapy.

The presence of IA-2 in secretory granule membranes in nearly all neuroendocrine tissues, combined with results from previously mentioned studies on the GH4C1 cell line (Solimena et al. 1996, Lee et al. 1998) has led to speculation on the association of IA-2 to regulated hormone secretion. We found, regardless of IA-2 expression, high expression of serotonin and CgA in normal EC cells and tumour, suggesting that IA-2 is not essential for the basal production of these hormones. It is more likely that IA-2 expression is necessary for distal events in the serotonin secretory pathway. In GH4C1 cells, IA-2 accumulation was very slow, reaching a maximum after 4 days of hormone stimulation. The EC cells examined were from fasting patients, thus secretion in general, and of serotonin especially, should be low (Ahlman 1976, Ahlman et al. 
IA-2 Antisense
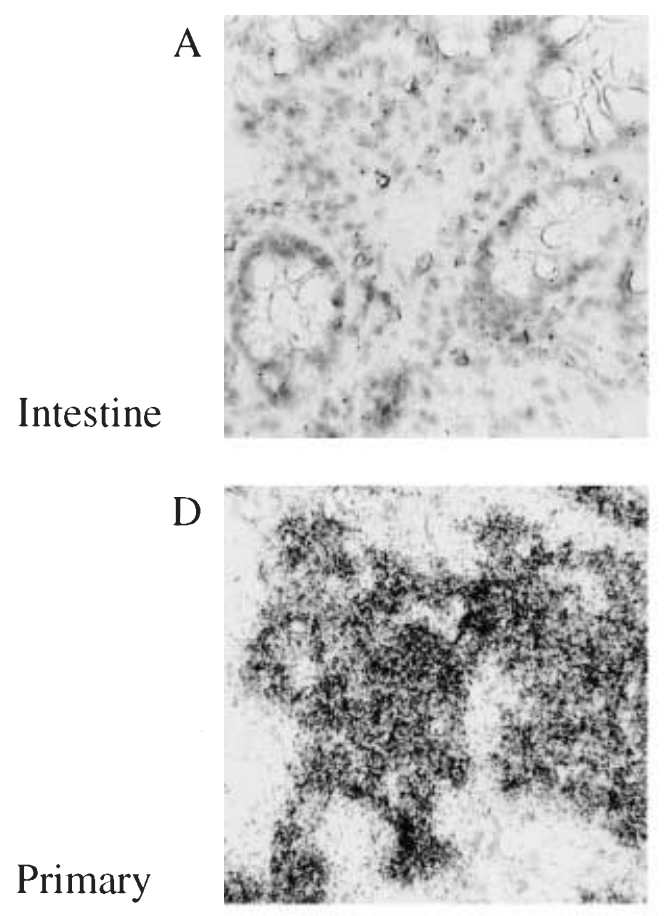

IA-2 Sense

$\mathrm{B}$

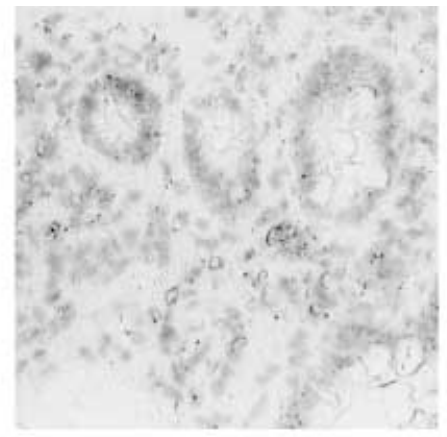

E

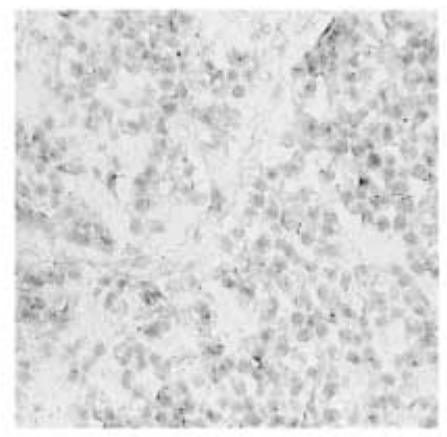

$\operatorname{CgA}$

C

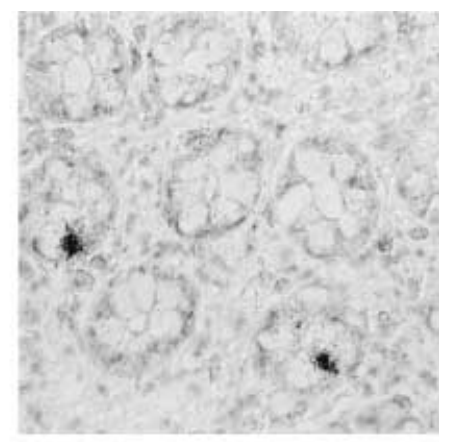

$\mathrm{F}$

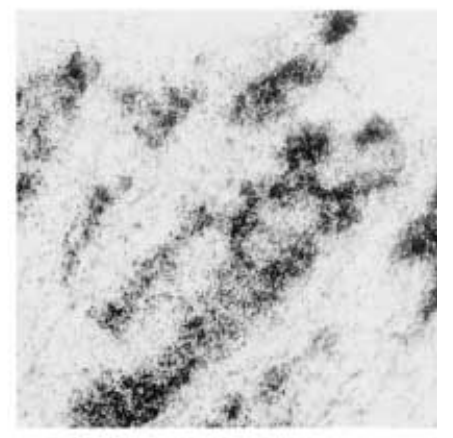

\section{Metastasis}
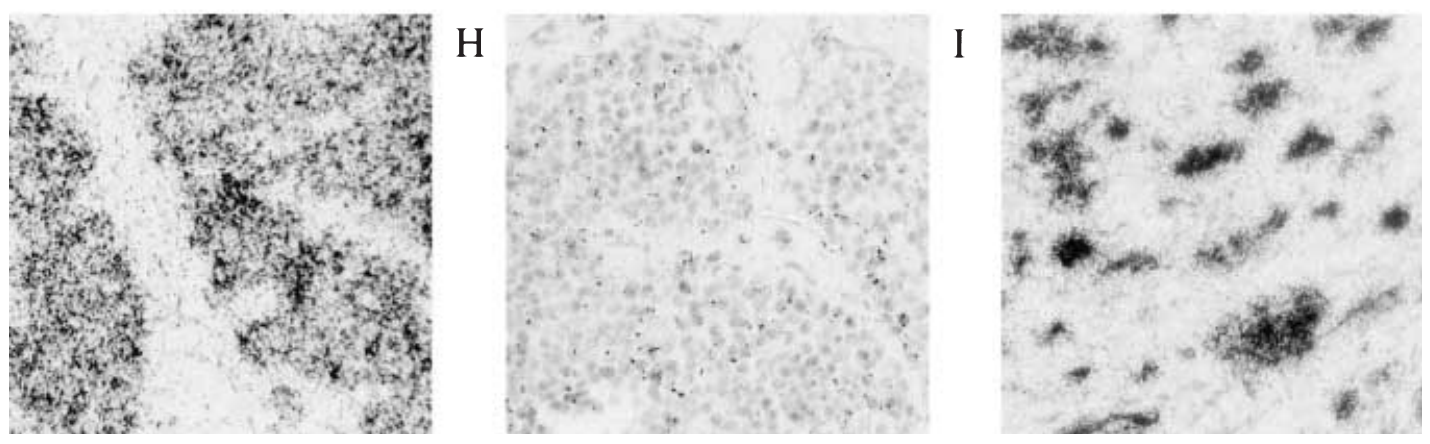

Figure 2 IA-2 mRNA expression was evaluated by in situ hybridisation with specific riboprobes. IA-2 mRNA was not detected in normal small intestine with an antisene riboprobe (A), while no specific hybridisation was observed with IA-2 sense control probe (B). The presence of mRNA in EC cells in the sample was confirmed by strong CgA mRNA expression (C). Primary tumour hybridised with IA-2 antisense probe gave a positive signal (D) and did not hybridise with IA-2 sense probe (E). The expression of CgA mRNA in the same tumour is shown in (F). Metastatic tumour also gave a positive signal with the IA-2 antisense probe (G) but did not specifically hybridise with IA-2 sense probe $(\mathrm{H})$. The expression of CgA mRNA in the same tumour is shown in (I).

1976a,b, Racke \& Schworer 1991, Racke et al. 1996) and, perhaps, not sufficient to allow a granular accumulation of IA-2. Carcinoid tumours characteristically demonstrate high secretion levels (Lawrence et al. 1990, Tiensuu Janson \& Oberg 1996, Westberg et al. 1997) and it is reasonable to assume that the tumour cells, at the time of operation, were actively secreting. Differences in IA-2 expression between normal EC cells and tumour cells may be due to differences in the amount of secretion stimulus they are receiving. It cannot, however, be excluded that the higher expression of IA-2 in tumours could represent a different secretion pathway.

Double staining of primary and metastatic tumours showed that co-localisation of IA-2 with serotonin was comparatively greater than co-localisation of IA-2 with chromogranin A, which displayed distinct fluorescence in the same cells but not in the same areas in all cases (Fig. 3G and H). Double staining of BON1 cells (Evers et al. 1994), a non-functioning pancreatic tumour cell line, displayed similar co-localisation (Fig. 3I and J). This is perhaps 
explained by possible heterogeneous mature granule populations and the different regulation of serotonin and chromogranin A secretion in EC cells. It is interesting to note that IA-2 and prolactin have been found to be co-localised but are possibly in separate granules from the granins (Gorr 1996). IA-2 is, perhaps, sorted to serotonincontaining granules, and differential IA-2 expression may reflect the differences in serotonin secretion of these neuroendocrine cells.
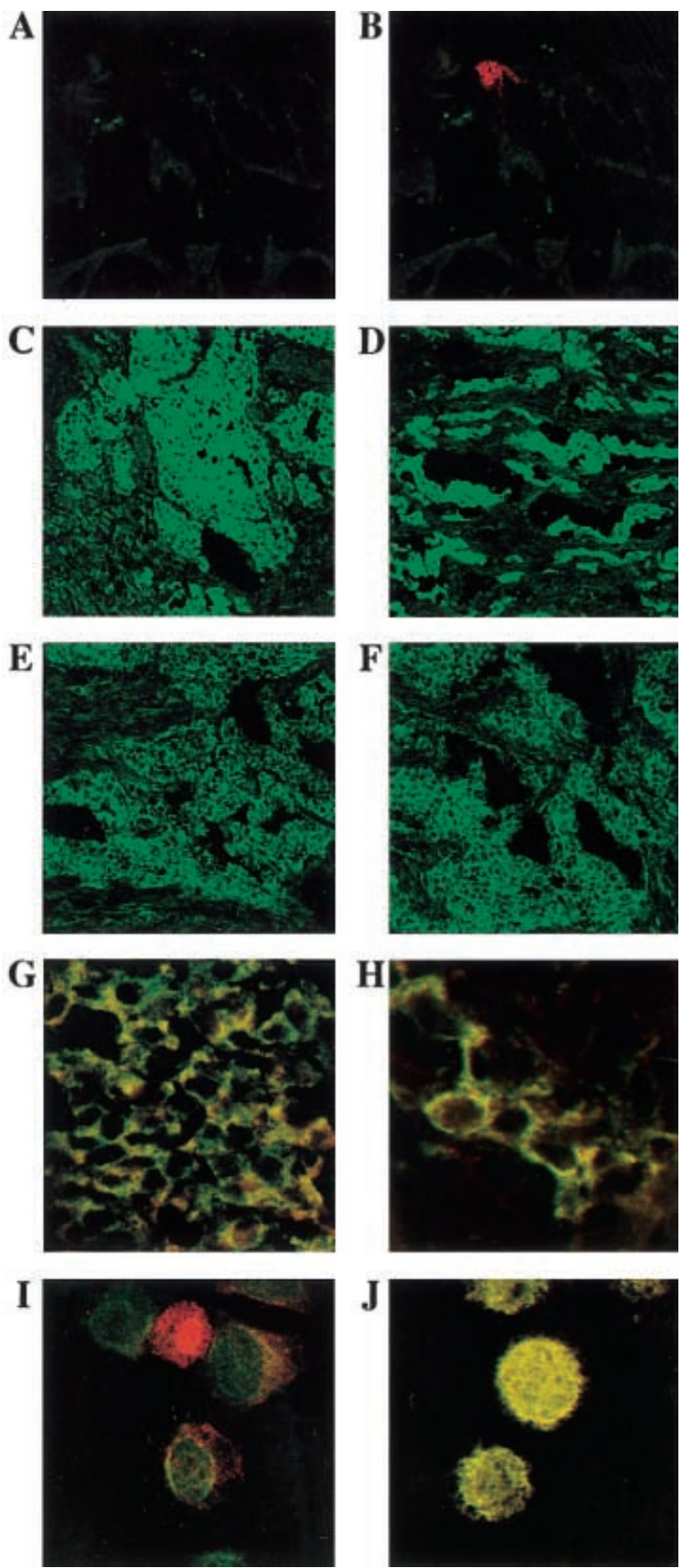

Although there is speculation concerning a role for IA-2 in growth regulation (Magistrelli et al. 1995), we could not find any correlation to growth rate in our patients (Table 1).

Support for a secretory role was also drawn from differences in IA-2 expression dependent on tumour biotherapy. $\alpha$-Interferon and octreotide treatments are both thought to inhibit secretion of hormones from tumour cells. $\alpha$-Interferon is thought to affect the translation rate of the cell (Oberg 1994), while somatostatin has been shown to inhibit secretion (Patel et al. 1997) as well as downregulating the expression of certain hormones (insulin, gastrin, glucagon) (Karnik et al. 1992, Redmon et al. 1994, Kendall et al. 1995). Although they target different stages of the secretory process, both of these treatments reduce levels of plasma chromogranin A and urine 5-hydroxyindoleacetic acid, the most potent reduction of hormone secretion being after a combination of these two therapies (Oberg 1994, Tiensuu Janson \& Oberg 1996). Accordingly, IA-2 expression was lower in patients that had received a combination of $\alpha$-interferon and octreotide prior to operation, probably reflecting a low secretory activity in the tumour cells. The clinical significance of this is still not fully elucidated but, in the future, measurement of IA-2 might be used to identify actively secreting, as opposed to non-secreting, tumour cells.

However, the exact role(s) and regulation of IA-2 in neuroendocrine secretory cells remains to be elucidated. Future studies should be directed at determining possible IA-2 protein interactions, as understanding of secretory mechanisms may offer new treatment possibilities for the symptomatic over-secretion that is the hallmark of these neuroendocrine tumours.

\section{Acknowledgements}

We thank Professor A Karlsson for valuable discussion and Dr Z Li for his expert advice in confocal microscopy and

Figure 3 Confocal imaging of sections stained by indirect immunofluorescence showed that IA-2 protein was not detectable in normal small intestine EC cells, using specific IA-2 antibodies and secondary FITC-labelled swine anti-rabbit IgG (A). On the other hand, these cells clearly stained for CgA, using a mouse monoclonal and Cy3-labelled goat anti-mouse secondary antibody (B) (magnification $\times 185)$. Patients that had not undergone treatment had higher levels of IA-2 protein in both the primary tumour and metastases ( $C$ and $D$ respectively), while primary tumour and metastases from patients who had received a combination of $\alpha$-interferon and octreotide demonstrated reduced IA-2 expression (E and F) (magnification $\times 109$ ). In carcinoid tumour tissue, IA-2 was partially localised with CgA (G) and more completely with serotonin $(\mathrm{H})$ (magnification $\times 309$ ). As in patient material, in the pancreatic tumour cell line, BON1, IA-2 co-localised partially with $\mathrm{CgA}$ (I) and more completely with serotonin $(\mathrm{J})$ (magnification $\times 247$ and $\times 273$ respectively). 
Table 1 IA-2 stain intensity and percentage of proliferating cells in thirteen patients divided into four different treatment categories

\begin{tabular}{|c|c|c|c|c|c|c|}
\hline & Sex & Treatment & Tumour status & IA-2 & Ki 67 (\%) & $\mathbf{P} / \mathbf{M}(\%)$ \\
\hline \multicolumn{7}{|c|}{ Patient } \\
\hline 1 & $\mathrm{~F}$ & Untreated & Stable & High & $0 \cdot 5$ & $0 \cdot 5$ \\
\hline 2 & M & Untreated & Stable & High & $0 \cdot 5$ & $2 \cdot 0$ \\
\hline 3 & $\mathrm{~F}$ & Untreated & Stable & High & $4 \cdot 5$ & 3 \\
\hline 4 & $\mathrm{~F}$ & Untreated & Stable & Medium & n.d. & $4 \cdot 5$ \\
\hline 5 & M & IFN & Stable & High & n.d. & $4 \cdot 5$ \\
\hline 6 & $\mathrm{~F}$ & IFN & Stable & High & n.d. & $6 \cdot 8$ \\
\hline 7 & M & IFN & Progressive & High & $3 \cdot 4$ & $5 \cdot 2$ \\
\hline 8 & $\mathrm{~F}$ & OCT & Stable & Medium & $0 \cdot 5$ & $0 \cdot 5$ \\
\hline 9 & $\mathrm{~F}$ & IFN/OCT & Stable & Low & $6 \cdot 8$ & n.d. \\
\hline 10 & M & IFN/OCT & Stable & Medium & 0 & $5 \cdot 9$ \\
\hline 11 & M & IFN/OCT & Progressive & Low & 0 & n.d. \\
\hline 12 & M & IFN/OCT & Progressive & Low & 0 & 5 \\
\hline 13 & $\mathrm{~F}$ & IFN/OCT & Progressive & Medium & $1 \cdot 5$ & $9 \cdot 5$ \\
\hline
\end{tabular}

Patients who were treated received $\alpha$-interferon (IFN), octreotide (OCT; a somatostatin analogue) or a combination of both. Stable status represents stable biochemical and radiological disease. The combination treatment group demonstrated lower IA-2 expression as estimated by confocal microscopy. As significant intensity differences between primary and metastatic tumours were not found, these results were combined. Ki 67 values assessed the proliferation rate of tumours and did not correlate to IA-2 expression. Percentages are rounded to the nearest half and based on cell counts in three separate areas the primary $(\mathrm{p})$ and metastasis $(\mathrm{m})$ tumour respectively. n.d., not done.

immunofluorescence techniques. This work was supported by Torsten and Ragnar Söderbergs Research Foundation, the Swedish Cancer Foundation and the Åke Wiberg Foundation.

\section{References}

Ahlman H 1976 Fluorescence histochemical studies on serotonin in the small intestine and the influence of vagal nerve stimulation. Acta Physiologica Scandinavia Supplement 437 1-30.

Ahlman H, Dahlstrom A, Kewenter J \& Lundberg J 1976a Vagal influence on serotonin concentration in enterochromaffin cells in the cat. Acta Physiologica Scandinavia 97 362-368.

Ahlman H, Lundberg J, Dahlstrom A \& Kewenter J 19766 A possible vagal adrenergic release of serotonin from enterochromaffin cells in the cat. Acta Physiologica Scandinavia 98 366-375.

Chomczynski P \& Sacchi N 1987 Single-step method of RNA isolation by acid guanidinium thiocyanate-phenol-chloroform extraction. Analytical Biochemistry 162 156-159.

Evers BM, Ishizuka J, Townsend CM Jr \& Thompson JC 1994 The human carcinoid cell line, BON. A model system for the study of carcinoid tumors. Annals of the New York Academy of Sciences $\mathbf{7 3 3}$ 393-406.

Gobl AE, Funa K \& Alm GV 1988 Different induction patterns of mRNA for IFN-alpha and -beta in human mononuclear leukocytes after in vitro stimulation with herpes simplex virus-infected fibroblasts and Sendai virus. Journal of Immunology 140 3605-3609.

Gorr SU 1996 Differential storage of prolactin, granins (chromogranin $\mathrm{B}$ and secretogranin II), and constitutive secretory markers in rat pituitary GH4C1 cells. Journal of Biological Chemistry 271 3575-3580.

Hendy GN, Bevan S, Mattei MG \& Mouland AJ 1995 Chromogranin A. Clinical Investigations in Medicine 18 47-65.
Karnik PS, Dushkin H \& Wolfe MM 1992 Somatostatin inhibition of gastrin gene expression: involvement of pertussis toxin-sensitive and -insensitive pathways. Regulatory Peptides 38 167-177.

Kendall DM, Poitout V, Olson LK, Sorenson RL \& Robertson RP 1995 Somatostatin coordinately regulates glucagon gene expression and exocytosis in HIT-T15 cells. Journal of Clinical Investigation 96 2496-2502.

Lan MS, Lu J, Goto Y \& Notkins AL 1994 Molecular cloning and identification of a receptor-type protein tyrosine phosphatase, IA-2, from human insulinoma. DNA and Cell Biology 13 505-514.

Langley K \& Grant N 1997 Are exocytosis mechanisms neurotransmitter specific? Neurochemistry International 31 739-757.

Lawrence JP, Ishizuka J, Haber B, Townsend CM Jr \& Thompson JC 1990 The effect of somatostatin on 5-hydroxytryptamine release from a carcinoid tumor. Surgery 108 1131-1135.

Lee MS, Dirkx R Jr, Solimena M \& Dannies PS 1998 Stabilization of the receptor protein tyrosine phosphatase-like protein ICA512 in GH4C1 cells upon treatment with estradiol, insulin, and epidermal growth factor. Endocrinology 139 2727-2733.

Magistrelli G, Covini N, Mosca M, Lippoli G \& Isacchi A 1995 Expression of PTP35, the murine homologue of the protein tyrosine phosphatase-related sequence IA-2, is regulated during cell growth and stimulated by mitogens in 3T3 fibroblasts. Biochemical and Biophysical Research Communications 217 154-161.

Magistrelli G, Toma S \& Isacchi A 1996 Substitution of two variant residues in the protein tyrosine phosphatase-like PTP35/IA-2 sequence reconstitutes catalytic activity. Biochemical and Biophysical Research Communications 227 581-588.

Notkins AL, Zhang B, Matsumoto Y \& Lan MS 1997 Comparison of IA-2 with IA-2beta and with six other members of the protein tyrosine phosphatase family: recognition of antigenic determinants by IDDM sera. Journal of Autoimmunity 10 245-250.

Oberg K 1994 Treatment of neuroendocrine tumors. Cancer Treatment Reviews 20 331-355. 
Patel YC, Galanopoulou AS, Rabbani SN, Liu JL, Ravazzola M \& Amherdt M 1997 Somatostatin-14, somatostatin-28, and prosomatostatin[1-10] are independently and efficiently processed from prosomatostatin in the constitutive secretory pathway in islet somatostatin tumor cells (1027B2). Molecular and Cellular Endocrinology 131 183-194.

Pelosi G, Bresaola E, Bogina G, Pasini F, Rodella S, Castelli P, Iacono C, Serio G \& Zamboni G 1996 Endocrine tumors of the pancreas: Ki-67 immunoreactivity on paraffin sections is an independent predictor for malignancy: a comparative study with proliferating-cell nuclear antigen and progesterone receptor protein immunostaining, mitotic index, and other clinicopathologic variables. Human Pathology 27 1124-1134.

Portela-Gomes GM, Stridsberg M, Johansson H \& Grimelius L 1997 Complex co-localization of chromogranins and neurohormones in the human gastrointestinal tract. Journal of Histochemistry and Cytochemistry 45 815-822.

Rabin DU, Pleasic SM, Palmer-Crocker R \& Shapiro JA 1992 Cloning and expression of IDDM-specific human autoantigens. Diabetes 41 183-186.

Rabin DU, Pleasic SM, Shapiro JA, Yoo-Warren H, Oles J, Hicks JM, Goldstein DE \& Rae PM 1994 Islet cell antigen 512 is a diabetes-specific islet autoantigen related to protein tyrosine phosphatases. Journal of Immunology 152 3183-3188.

Racke K \& Schworer H 1991 Regulation of serotonin release from the intestinal mucosa. Pharmacology Research 23 13-25.
Racke K, Reimann A, Schworer H \& Kilbinger H 1996 Regulation of 5-HT release from enterochromaffin cells. Behaviour and Brain Research 73 83-87.

Redmon JB, Towle HC \& Robertson RP 1994 Regulation of human insulin gene transcription by glucose, epinephrine, and somatostatin. Diabetes 43 546-551.

Smith PD, Barker KT, Wang J, Lu YJ, Shipley J \& Crompton MR 1996 ICAAR, a novel member of a new family of transmembrane, tyrosine phosphatase-like proteins. Biochemical and Biophysical Research Communications 229 402-411.

Solimena M, Dirkx R Jr, Hermel JM, Pleasic-Williams S, Shapiro JA, Caron L \& Rabin DU 1996 ICA512, an autoantigen of type I diabetes, is an intrinsic membrane protein of neurosecretory granules. EMBO Journal 15 2102-2114.

Tiensuu Janson EM \& Oberg KE 1996 Carcinoid tumours. Baillieres Clinical Gastroenterology 10 589-601.

Westberg G, Ahlman H, Nilsson O, Illerskog A \& Wangberg B 1997 Secretory patterns of tryptophan metabolites in midgut carcinoid tumor cells. Neurochemistry Research 22 977-983.

Xie H, Notkins AL \& Lan MS 1996 IA-2, a transmembrane protein tyrosine phosphatase, is expressed in human lung cancer cell lines with neuroendocrine phenotype. Cancer Research 56 $2742-2744$.

Received 12 May 1999

Accepted 23 September 1999 